\title{
Usefulness of Quantitative and Qualitative Angiographic Lesion Morphology, and Clinical Characteristics in Predicting Major Adverse Cardiac Events During and After Native Coronary Balloon Angioplasty
}

\author{
Walter R. M. Hermans, MD, David P. Foley, MB, MRCPI, Benno J. Rensing, MD, \\ Wolfgang Rutsch, MD, Guy R. Heyndrickx, MD, Nicolas Danchin, MD, Gijs Mast, MD, \\ Claude Hanet, MD, Jean-Marc Lablanche, MD, Wolfgang Rafflenbeul, MD, Rainer Uebis, MD, \\ Raphael Balcon, MD, Pim J. de Feyter, MD, and Patrick W. Serruys, MD, \\ on Behalf of the CARPORT and MERCATOR Study Groups*
}

\begin{abstract}
Major, adverse cardiac events (death, myocardial infarction, bypass surgery and reintervention) occur in 4 to $7 \%$ of all patients undergoing coronary balloon angioplasty. Prospectively collected clinical data, and anglographic quantitative and qualitative lesion morphologic assessment and procedural factors were examined to determine whether the occurrence of these events could be predicted. Of 1,442 patients undergoing balloon angioplasty for native primary coronary disease in 2 European multicenter trials, 69 had major, adverse cardiac procedural or inhospital complica tions after $\geq 1$ balloon inflation and were randomly matched with patients who completed an uncomplicated in hospital course after successful angioplasty. No quantitative angiographic variable was associated with major adverse cardiac events in univariate and multivariate analyses. Univariate analysis showed that major adverse cardiac events were associated with the following preprocedural variables: (1) unstable angina (odds ratio [OR] 3.11; p <0.0001), (2) type C lesion (OR 2.53; $p<0.004)$, (3) lesion location at a bend $>45^{\circ}$ (OR 2.34; p <0.004), and (4) stenosis located in the middle segment of the artery dilated (OR 1.88; p $<0.03$ ); and with the following postprocedural variable: angiographically visible dissection (OR 5.39; p <0.0001). Multivariate logistic analysis was performed to identify variables independently corre-
\end{abstract}

\footnotetext{
From Thoraxcenter, Rotterdam, the Netherlands; Universitäts Klinikum Virchow, Berlin, Germany; Cardiovascular Center Onze Lieve Vrouw Ziekenhuis, Aalst, Belgium; CHU Brabois, Vandoeuvre, France; St. Antonius Ziekenhuis, Nieuwegein, the Netherlands; St. Luc University Hospital, Brussels, Belgium; CHRU-Hôpital Cardiologique, Lille, France; Medizinische Hochschule, Hannover, Germany; Medizinische Klinik I, Aachen, Germany; and the London Chest Hospital, London, United Kingdom. Manuscript received November 16, 1992; revised manuscript received February 3, 1993, and accepted February 5.

Address for reprints: Patrick W. Serruys, MD, Catheterization Laboratory, Thoraxcenter, Erasmus University, P.O. Box 1738, 3000 DR Rotterdam, the Netherlands.
}

\footnotetext{
*Complete listings of the CARPORT and MERCATOR investigators appear in references 15 and 16.
}

lated with the occurrence of major adverse cardac events. The preprocedural multivariate model entered unstable angina (OR 3.77; $p<0.0003$ ), lesions located at a bend $>45^{\circ}$ (OR 2.87; $p<0.0005$ ), and stenosis located in the middle portion of the artery dilated (OR 1.95; $p<0.04$ ). If all variables were included, then angiographically visible dissection (OR 6.58; $p<0.0001$ ), unstable angina (OR 3.46; $p<0.002$ ) and lesions located at $a$ bend $>45^{\circ}$ (OR 2.54; $p<0.006$ ) were independent predictors of major adverse cardiac events.

(Am J Cardiol 1993;72:14-20)

I n the initial "National Heart, Lung, and Blood Institute Percutaneous Transluminal Coronary Angio1 plasty Registry" publication, which described the immediate results of patients treated by balloon angioplasty, major adverse cardiac events (i.e., death, myocardial infarction, coronary artery bypass grafting and repeat dilatation) were reported in $13.6 \%$ of patients. ${ }^{1}$ Because of improvement in operator experience, as well as radiographic equipment and balloon catheter design over the succeeding 5 years, this percentage decreased to 4 to $7 \%$, despite extension of the indications for coronary balloon angioplasty to include patients aged $>70$ years, and those with multivessel disease or poor left ventricular function, prior bypass surgery, and more severe and complex lesions. ${ }^{2-6}$ Many clinical factors such as multivessel disease, female gender, unstable angina and multiple lesions, as well as qualitative angiographic lesion morphology, including cccentricity, presence of calcium, lesion length, stenosis at a bend, stenosis at a branch point, presence of thrombus, and complex lesions, have been suggested to be predictors of a major procedural or in-hospital cardiac event. ${ }^{3-9}$ Previous studies used visual interpretation of the coronary angiogram, which is now known to be limited by considerable interand intraobserver variability. ${ }^{10-12}$ Thus, quantitative coronary angiographic systems are now the "gold standard" for objective geometric assessment of coronary narrowings, and for assessing the short- and long-term results of interventions. ${ }^{13,14}$ In addition to the actual degree of lumen narrowing, these quantitative coronary 
systems can also provide detailed lesion morphologic characteristics such as lesion length, atherosclerotic plaque area, lesion eccentricity and vessel curvature. ${ }^{13}$ The present study investigated whether comprehensive evaluation of lesion morphology by quantitative coronary analysis, in addition to conventional qualitative assessment, and inclusion of baseline, clinical characteristics and procedural details, could identify patients at particularly high risk for major procedural or in-hospital adverse cardiac events. The identification of risk factors for the occurrence of these complications may be of considerable clinical value in deciding which patients or lesions would be suitable for an alternative treatment to balloon angioplasty.

\section{METHODS}

In all, 1,442 patients were enrolled in 2 randomized, double-blind, placebo-controlled, restenosis prevention trials (CARPORT [ $\mathrm{n}=707]$ and MERCATOR [ $\mathrm{n}=$ 735]) between December 1987 and June 1990. Neither trial (described in detail previously) found any clinical or angiographic benefit from the agent under investigation. ${ }^{15,16}$ For the purpose of this ancillary study, the patient cohort comprised those who had major procedural or in-hospital complications (as previously defined) after $\geq 1$ balloon inflation, regardless of the final result of balloon angioplasty (group $\mathrm{I} ; \mathrm{n}=69$ ). Each patient in group I was randomly matched with 3 control patients by the date of angioplasty (to the nearest week in the same hospital) (group II; $n=207$ ) to assess the predictability of major adverse cardiac events. In cases of multilesion dilatation, the most severe lesion was selected and used for comparison. Each available cineangiogram was separately reviewed by 2 experienced interventionalists who were unaware of clinical or procedural information, or the outcome of intervention.

Percutaneous transluminal coronary angioplasty procedure and anglographic analysis: At the beginning of the angioplasty procedure, all patients received a bolus of $10,000 \mathrm{IU}$ of intravenous heparin; for prolonged procedures, an additional infusion of 5,000 IU/hour was commenced after 2 hours and continued until the end of the procedure. Aspirin was routinely administered to all patients in the MERCATOR trial and to those randomized to placebo in the CARPORT trial. ${ }^{15,16}$ Use of a calcium antagonist was permitted for 24 to 48 hours after coronary balloon angioplasty. The choices of guiding catheter, guide wire, balloon type, inflation duration and pressure were made by the operator. Primary angioplasty success was defined at the time the guide catheter was removed as diameter stenosis $<50 \%$ by visual estimation, without the occurrence of a major adverse cardiac event.

At least 2 angiographic projections (orthogonal if possible) were recorded in such a way that they were suitable for quantitative analysis by the Coronary Angiography Analysis System, which was validated and described in detail previously. ${ }^{13}$ An example of an analysis is shown in Figure 1.

The absolute stenosis and reference diameters were measured by the computer using the known contrastempty, guiding catheter diameter as a scaling device. For that purpose, the catheter tips were retained for accurate measurement with a micrometer. To achieve maximal coronary vasodilation, either nitroglycerin ( 0.1 to 0.3 $\mathrm{mg}$ ) or isosorbide dinitrate (1 to $3 \mathrm{mg}$ ) was administered (intracoronary) to each affected coronary artery before angiography. All contour positions of the catheter and arterial segment were corrected for "pincushion distortion" introduced by the image intensifiers. Because the algorithm cannot measure total occlusions or lesions with Thrombolysis in Myocardial Infarction grade 1 perfusion, a value of $0 \mathrm{~mm}$ was substituted for the minimal lumen diameter and $100 \%$ for percent diameter stenosis in such cases.

Variables used in the analysis: BASELINE CLINICAL CHARACTERISTICS: The following patient-related variables were recorded in the patient files: age, gender, duration of angina, cholesterol level, previous myocardial infarction, current smoking, diabetes mellitus, extent of atherosclerotic disease (single or multivessel), Canadian Cardiovascular Society angina classification, and unstable angina (defined as pain at rest needing treatment with intravenous nitrates). ${ }^{17}$

QUALITATIVE ANGIOGRAPHIC CHARACTERISTICS: The following qualitative lesion parameters were assessed: (1) vessel dilated (right, left anterior descending or left circumflex); and (2) location of the stenosis in the vessel dilated, according to the numeric scheme proposed by Austen et al. ${ }^{18}$ The following subdivisions were used for location of the stenosis: proximal corresponding with segments 1, 6 and 11; middle corresponding with segments $2,7,13$ and 15; distal corresponding with seg-

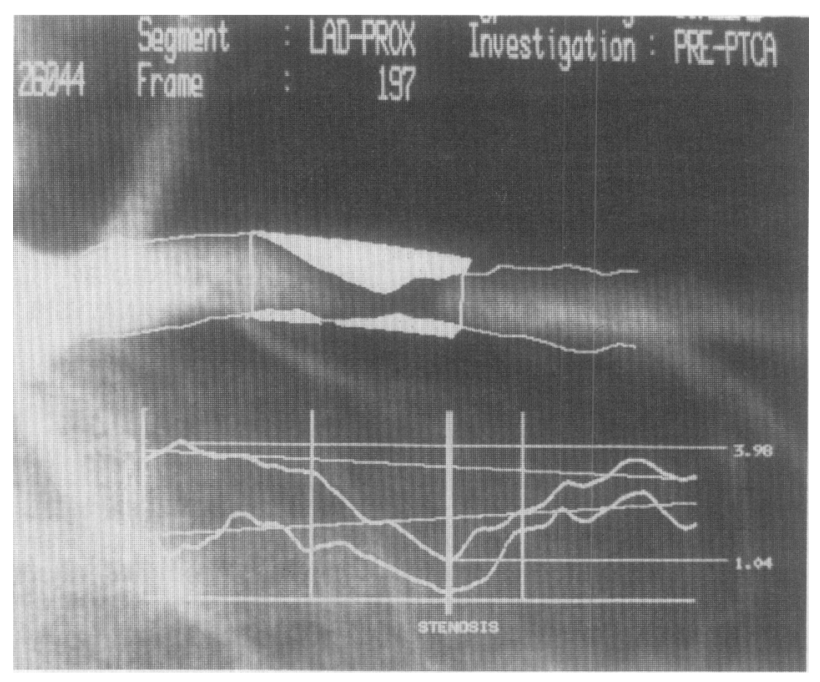

FICURE 1. Single-frame angiogram of proximal left anterior descending (LAD) artery stenosis before dilatation in right anterior oblique $\left(30^{\circ}\right)$ projection. Quantitative coronary anaf ysis was performed using Cardiovascular Angiography Analysis System. Arterial boundaries automatically detected by system are shown on angiogram, and diameter function curve derived from these contours by interpolating is shown in middle part of figure (upper curve). Lower horizontal line (1.04 mm) is minimal lumen diameter. Outside vertical lines on graph, and 2 vertical lines on angiogram are lesion boundaries (lesion length $8.6 \mathrm{~mm}$ ). Innermost vertical line is position of minimal luminal diameter, and point where this line intersects diameter function curve (upper horizontal line) is considered reference diameter ( $3.25 \mathrm{~mm}$; value not shown). Lesion length is automatically determined by curva ture analysis of detected vessel contours. 
ments 8 to 10,12 and 14; (3) type of lesion, defined by a modified Ambrose classification, as follows: concentric, eccentric (a stenosis asymmetrically positioned in the vessel in any nonforeshortened angiographic projection), tandem ( 2 discrete lesions in the same coronary segment separated by an apparently normal segment), multiple irregularities ( $\geq 2$ serial diffuse irregularities in the same coronary segment), and totally occluded vessel ${ }^{19}$; (4) a bend $>45^{\circ}$ was considered present if in any nonforeshortened projection, the balloon in position to dilate was located in a portion of the vessel with a $\geq 45^{\circ}$ angulation at end-diastole 20 ; (5) presence of a side branch in the lesion to be dilated; (6) presence of a side branch, separate from the actual lesion but within the dilated segment; (7) presence of intracoronary thrombus (a noncalcified filling defect within the lumen, surrounded by contrast material observed in multiple projections or the persistence of contrast material within the lumen, or a visible embolization of intraluminal material "downstream") ${ }^{21}$; (8) presence of calcification (defined as fixed radiopaque densities in the area of the stenosis to be dilated); and (9) type of lesion (A, B or C) according to the American College of Cardiology/American Heart Association Task Force. 22

QUANTITATIVEL Y ANGIOGRAPHIC CHARACTERISTICS: The following quantitative measurements were obtained: mini-

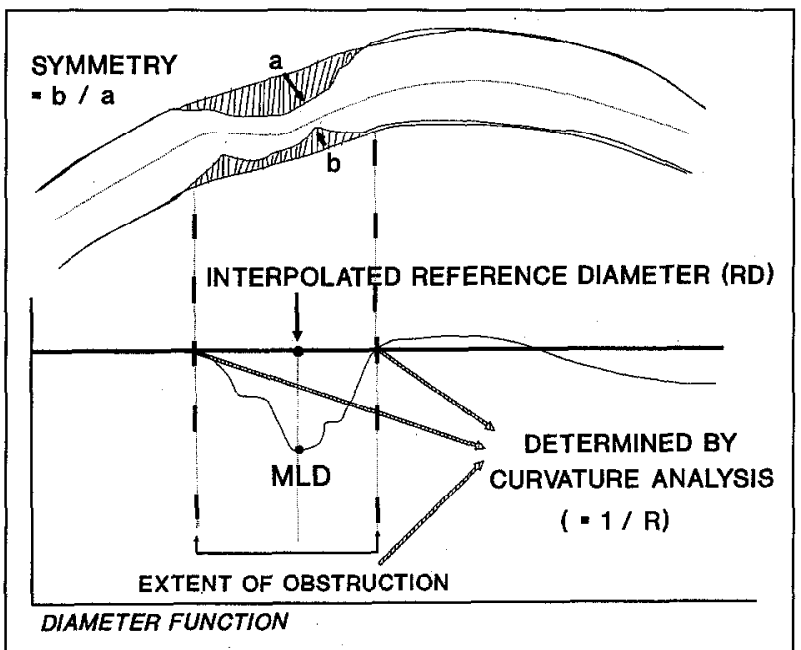

FICURE 2. Area between actual and reconstructed contours at obstruction site is measure of amount of atherosclerotic plaque. Length of obstruction is determined from diameter function on basis of automatically detected curvature analysis without interference by analyst. Syminetry is defined as coefficient of left- and righthand distance between reconstructed interpolated reference diameter and actual vessel contours at site of obstruction. In this equation, largest distance between actual and reconstructed contours becomes denominator, so that symmetrical lesion has value of 1, and a severely eccentric lesion has value of 0 . To assess extent of coronary bending, curvature value at obstruction site is computed as average value of all individual curvature val ues along centerline of coronary segment, with curvature defined by rate of change of angle through which tangent to curve tums in moving along curve, and which for circle is equal to reciprocal of radius. Curvature value and symmetry index are determined in projection in least foreshortened view (in which analyzed segment was longest between 2 defined landmarks and is expressed as continuous integer value, ranging from 0 for straight segment to 90 for segment with $90^{\circ}$ bend). MLD = minimal lumen diameter. mal lumen and interpolated reference diameters, diameter stenosis, lesion length and eccentricity, atherosclerotic plaque area and vessel curvature (Figure 2).

PROCEDURAL FACTORS: Balloon-artery ratio was used to assess the suitability of the balloon size for the vessel segment, and was defined as the ratio between the measured mean balloon size and the (interpolated) reference diameter of the dilated segment. Angiographically visible dissections were defined according to modified National Heart, Lung, and Blood Institute criteria. ${ }^{22}$

Reproducibility of morphologic assessment: Interobserver variability of the 2 reviewers for qualitative lesion assessment was examined in an arbitrarily selected number of lesions. The coronary angioplasty films of 138 patients with 151 lesions (consecutive films reaching the core laboratory) were independently assessed for the diverse lesion morphologic characteristics by each observer on 2 separate occasions, 3 months apart, with blinding for earlier assessment. Interobserver discordance was as follows: lesion eccentricity $21 \%$; branch point location 29\%; branch point location in dilated segment $19 \%$; bend point location $14 \%$; presence of thrombus $2 \%$; presence of calcification $10 \%$; presence of dissection $11 \%$; and lesion type according to the American College of Cardiology/American Heart Association Task Force classification $25 \%$.

Statistical analysis: Analyses were performed to test the hypothesis that clinical, qualitative and quantitative lesion morphologic and procedural characteristics are important determinants of major adverse cardiac events. The risk of major cardiac adverse events for each variable was expressed as an odds ratio: (probability of an event variable present/probability of no event variable present)/(probability of an event variable absent/probability of no event variable absent).

Continuous variables were dichotomized by cut points derived by dividing the data into 2 groups, each containing approximately $50 \%$ of the population. This method of subdivision has the advantage of being consistent for all variables and thus avoids any bias in selection of subgroups, which may be performed to emphasize a particular point. An odds ratio (OR) of 1 for a particular variable suggests that its presence poses no additional risk for a major event. An OR $>$ or $<1$ suggests additional or reduced risk, respectively. The $95 \%$ confidence intervals (CI) were calculated to describe the statistical certainty. If the CI included 1, no significant increased or reduced risk was deemed to be conferred by the variable. Multivariate analysis by multiple logistic regression was performed to identify variables independently correlated with the occurrence of a major cardiac, procedural or in-hospital adverse event, using only those variables significant at the $p<0.1$ level in the univariate analysis. All statistical analyses were performed with a commercial statistical package (BMDP Statistical Software Package 1990).

\section{RESULTS}

Of 1,442 patients recruited, balloon angioplasty was not performed in 9 patients, because the lesion severity had changed or because of equipment failure. A further 43 patients had (sub)totally occluded lesions that could 


\begin{tabular}{|c|c|c|c|}
\hline Variable & $\begin{array}{l}\text { Patient Positive } \\
\text { for Variable } \\
\text { (event/total) }\end{array}$ & $\begin{array}{l}\text { Patient Negative } \\
\text { for Variable } \\
\text { (event/total) }\end{array}$ & Odds Ratio $(95 \% \mathrm{Cl})$ \\
\hline Myocardial infarction (history) & $23 / 107$ & $46 / 169$ & $0.73(0.41$ to 1.30$)$ \\
\hline Currently smoking & $10 / 45$ & $59 / 231$ & $0.83(0.39$ to 1.79$)$ \\
\hline Multivessel coronary narrowing & $29 / 117$ & $39 / 146$ & $0.89(0.51$ to 1.51$)$ \\
\hline Diabetes mellitus & $6 / 25$ & $63 / 251$ & $0.94(0.36$ to 2.46$)$ \\
\hline Age $(<58$ years $)$ & $35 / 136$ & $34 / 140$ & $1.08(0.63$ to 1.86$)$ \\
\hline Duration of angina ( $>142$ days) & $35 / 137$ & $31 / 135$ & $1.15(0.66$ to 2.01$)$ \\
\hline $\begin{array}{l}\text { Total cholesterol } \\
\qquad(<6.2 \mathrm{mmol} / \mathrm{L} ;<240 \mathrm{mg} / \mathrm{dl})\end{array}$ & $34 / 129$ & $27 / 132$ & $1.39(0.78$ to 2.48$)$ \\
\hline $\begin{array}{l}\text { Canadian Cardiovascular Society } \\
\text { class III or IV }\end{array}$ & $47 / 169$ & $21 / 100$ & $1.45(0.81$ to 2.61$)$ \\
\hline Men & $59 / 221$ & $10 / 55$ & $1.64(0.78$ to 3.46$)$ \\
\hline Unstable angina & $29 / 69$ & $39 / 206$ & $3.11(1.72$ to 5.61$)$ \\
\hline
\end{tabular}

\begin{tabular}{|c|c|c|c|}
\hline Variable & $\begin{array}{l}\text { Patient Positive } \\
\text { for Variable } \\
\text { (event/total) }\end{array}$ & $\begin{array}{l}\text { Patient Negative } \\
\text { for Variable } \\
\text { (event/total) }\end{array}$ & Odds Ratio $(95 \% \mathrm{Cl})$ \\
\hline \multicolumn{4}{|l|}{ Coronary artery dilated } \\
\hline Right & $15 / 67$ & $54 / 209$ & $0.83(0.43$ to 1.59$)$ \\
\hline Left circumflex & $17 / 72$ & $52 / 204$ & $0.90(0.48$ to 1.69$)$ \\
\hline Left anterior descending & $37 / 137$ & $32 / 139$ & $1.24(0.72$ to 2.14$)$ \\
\hline Multiple site dilated & $12 / 45$ & $57 / 231$ & $1.11(0.54$ to 2.29$)$ \\
\hline Total occlusion & $8 / 24$ & $61 / 252$ & $1.57(0.64$ to 3.84$)$ \\
\hline Middle portion of vessel dilated & $36 / 112$ & $33 / 164$ & $1.88(1.08$ to 3.26$)$ \\
\hline \multicolumn{4}{|l|}{$\begin{array}{l}\text { Lesion morphalogy quantitatively derived } \\
\text { before angioplasty }\end{array}$} \\
\hline Symmetry index $(<0.34)^{*}$ & $30 / 121$ & $32 / 131$ & $1.00(0.56$ to 1.77$)$ \\
\hline Minimal lumen diameter $(>0.98 \mathrm{~mm})$ & $35 / 139$ & $34 / 137$ & $1.02(0.59$ to 1.76$)$ \\
\hline Diameter stenosis ( $<62 \%)$ & $35 / 136$ & $34 / 140$ & $1.08(0.63$ to 1.86$)$ \\
\hline Length lesion $(>5.8 \mathrm{~mm})^{*}$ & $32 / 127$ & $29 / 125$ & $1.12(0.63$ to 1.99$)$ \\
\hline Vessel size (>2.53 mm) & $37 / 140$ & $30 / 134$ & $1.25(0.72$ to 2.17$)$ \\
\hline Atherosclerotic plaque $\left(>6.1 \mathrm{~mm}^{2}\right)^{*}$ & $35 / 127$ & $26 / 125$ & $1.45(0.81$ to 2.59$)$ \\
\hline Curvature index $(>19)^{*}$ & $37 / 128$ & $24 / 124$ & $1.69(0.94$ to 3.05$)$ \\
\hline \multicolumn{4}{|l|}{ Lesion morphology; qualitative assessment } \\
\hline Side branch in area of balloon & $46 / 186$ & $20 / 80$ & $0.99(0.54$ to 1.81$)$ \\
\hline Calcified lesion & $9 / 33$ & $57 / 233$ & $1.16(0.51$ to 2.63$)$ \\
\hline Side branch in stenosis & $38 / 144$ & $28 / 122$ & $1.20(0.69$ to 2.11$)$ \\
\hline Eccentric located stenosis & $36 / 130$ & $30 / 136$ & $1.31(0.75$ to 2.28$)$ \\
\hline Bend $>45^{\circ}$ & $31 / 86$ & $35 / 180$ & $2.34(1.31$ to 4.15$)$ \\
\hline Type Clesion & $19 / 46$ & $47 / 220$ & $2.53(1.32$ to 4.86$)$ \\
\hline \multicolumn{4}{|l|}{ Procedural variables } \\
\hline Balloon-artery ratio $(>1.02)$ & $17 / 110$ & $16 / 105$ & $1.02(0.48$ to 2.14$)$ \\
\hline Thrombus after dilatation & $4 / 7$ & $62 / 259$ & $4.31(0.94$ to 19.80$)$ \\
\hline Intimal tear or dissection & $47 / 111$ & $19 / 155$ & $5.39(2.90$ to 10.00$)$ \\
\hline
\end{tabular}

be neither reached nor crossed with the guide wire or balloon catheter. Thus, of 1,390 patients in whom balloon dilatation was actually performed, 69 had a major adverse cardiac event. Myocardial infarction occurred during or shortly after the procedure in 15 patients $(1 \%)$ and during the hospital stay in an additional $22(1.5 \%)$. Emergency coronary bypass graft surgery was necessary immediately after unsuccessful coronary balloon angioplasty in 18 patients (1.3\%), and the indication for surgery occurred after leaving the catheterization laboratory in a further $9(1 \%)$. In 5 patients, a redilatation was performed during the hospital stay. No patient died during the procedure or hospital stay.
Clinical characteristics as predictors of major adverse cardiac events (Table I): Patients with unstable angina had more coronary events than did those without unstable angina (OR 3.11; p <0.0001; 95\% CI 1.72 to 5.61). Age, gender, duration of angina, serum cholesterol, history of myocardial infarction, diabetes mellitus, multivessel disease and Canadian Cardiovascular Society angina class did not influence the occurrence of a major adverse cardiac event.

Anglographic lesion characteristics as predictors of major adverse cardiac evenits (Table II): Location of the target lesion in the middle segment of the coronary artery dilated (OR 1.88; $\mathrm{p}<0.03 ; 95 \% \mathrm{CI} 1.08$ to 
3.26), lesions located at a bend $>45^{\circ}$ (OR 2.34; $p$ $<0.004 ; 95 \% \mathrm{CI} 1.31$ to 4.15 ), and type C lesions (OR $2.53 ; \mathrm{p}<0.004 ; 95 \%$ CI 1.32 to 4.86 ) were significantly associated with the occurrence of major adverse cardiac events; no other lesion morphologic characteristic (whether assessed qualitatively or by quantitative analysis) predicted subsequent development of these events.

Procedural predictors of major adverse cardiac events: The presence of any type of angiographically visible dissection after the procedure was strongly associated with the subsequent occurrence of a major adverse cardiac event (OR 5.39; $\mathrm{p}<0.0001 ; 95 \%$ CI 2.9 to 10.0). Neither thrombus after dilatation nor balloon-artery ratio was found to be predictive of major adverse cardiac events (Table II).

Logistic regression analysis: In considering only baseline preprocedural factors, the model entered unstable angina (OR 3.77; p <0.0003; 95\% CI 1.89 to 7.48 ), lesions located at a bend $>45^{\circ}$ (OR 2.87; $\mathrm{p}<0.0005$; 95\% CI 1.47 to 5.59 ), and stenosis located in the middle portion of the artery dilated (OR $1.95 ; p<0.04 ; 95 \%$ CI 1.01 to 2.74$)$. When postprocedural variables were added, then unstable angina (OR 3.46; $\mathrm{p}<0.002 ; 95 \%$ CI 1.67 to 7.17 ), lesions located at a bend $>45^{\circ}$ (OR $2.54 ; \mathrm{p}<0.006 ; 95 \% \mathrm{CI} 1.26$ to 5.13 ), and angiographically visible dissection (OR 6.58; $\mathrm{p}<0.0001 ; 95 \% \mathrm{CI}$ 3.17 to 13.7$)$ were independent predictors of major adverse cardiac events.

\section{DIScussion}

Despite the improvements in equipment and technique that have made it possible to dilate $>90$ to $95 \%$ of coronary obstructions, the occurrence of procedural and in-hospital cardiac adverse events due to acute or subacute vessel closure continues to be largely unpredictable. The reported frequency of so-called major cardiac adverse events depends on the time window applied after the patient left the catheterization laboratory 1 to $2 \%$, or during and after the procedure 4 to $7 \%$. In the present study, major adverse cardiac events were observed in 33 of 1,390 patients $(2.4 \%)$ after $\geq 1$ balloon inflation in the catheterization room and in a further 36 (2.6\%) during the hospitalization period.

Risk factors of major procedural and inhospital adverse cardiac events: In 1988, Ellis et $\mathrm{al}^{3}$ reported the results of 4,772 procedures performed between April 1, 1982 and March 31, 1986, and found (using multivariate analysis) 7 independent preprocedural factors related to abrupt vessel closure: stenosis length $\geq 2$ lumen diameters, female gender, stenosis at a bend point $\geq 45^{\circ}$, stenosis at a branch point, stenosis-associated thrombus (filling defect or staining), other stenoses in the same vessel, and multivessel disease. They concluded that although an estimation of risk can be obtained before performing coronary balloon angioplasty, the most powerful predictors of closure can only be assessed during the procedure (postangioplasty percent diameter stenosis, intimal tear or dissection, and prolonged postangioplasty use of heparin). The 1985-1986 National, Heart, Lung, and Blood Institute Percutaneous Transluminal Coronary Angioplasty Registry study analyzed 1,801 patients, and revealed that baseline factors inherently associated with increased occlusion rates included 3-vessel disease, high-risk status for surgery, and acute coronary insufficiency, and lesion characteristics included severe stenosis before coronary angioplasty, diffuse disease or multiple discrete lesions, thrombus and collateral flow from the lesion. De Feyter et al ${ }^{5}$ reported an acute coronary artery occlusion rate of $7.3 \%$ (total population 1,423 ), with unstable angina, multivessel disease and complex lesions as predictors for closure during or after the procedure.

In all the aforementioned studies that involved large groups of patients, lesion characteristics were visually assessed. No data are available on the predictability of major cardiac complications from quantitative coronary analysis, which has now emerged as the gold standard for assessment of long-term angiographic outcome of percutaneous transluminal coronary interventions. ${ }^{15,16}$ In addition to the "simple" quantitative parameters of minimal lumen (obstruction) diameter, reference diameter (or vessel size) and percent diameter stenosis, quantitative analysis computes length of the obstruction, area of atherosclerotic plaque, symmetry index of the stenosis, and curvature of the vessel. In the present study, quantitative coronary analysis was combined with assessment of qualitative lesion morphology and clinical characteristics to determine whether this thorough, integrated approach could improve the prediction of major adverse cardiac events.

The present results are in agreement with those of the earlier published studies showing that unstable angina, lesions located at a bend $>45^{\circ}$, and angiographically visible dissection after angioplasty were independent predictors of major procedural or in-hospital cardiac events. Lesion morphology as assessed by quantitative coronary analysis was not useful for the prediction of major adverse cardiac events.

The well-described association of unstable angina with the occurrence of major adverse cardiac events was confirmed in this study. Patients presenting with the clinical syndrome of unstable angina continue to provide the clinician with the difficult task of selecting a suitable management strategy that usually needs to be applied on an urgent basis. The increasing use of intracoronary angioscopy may be helpful in substratifying these patients and therefore guiding therapeutic strategies that may improve short- and long-term outcome. ${ }^{23}$

The location of the target lesion in a bend $>45^{\circ}$ was previously identified by Ellis et $\mathrm{al}^{3}$ as a risk factor for acute vessel closure. Their explanation was that the balloon must necessarily tear an atherosclerotic fixed and rigid bend lesion, as it straightens and stretches the lesion. In addition, the maximal stress is several times greater when there is a geometric discontinuity in the object to which the stress is applied.

The association of midsegment balloon dilatation with a greater risk of major adverse cardiac events is not readily explicable and could simply be a chance finding.

The most powerful predictor for major adverse cardiac events is the occurrence of an angiographically visible dissection after angioplasty, which is not surprising 
because all patients with procedural events had a dissection with flow limitation on their postdilatation angiogram, in agreement with previous reports. ${ }^{3,9}$

Other investigators have found that thrombus on the predilatation angiogram was predictive for a major adverse cardiac event. ${ }^{3-5}$ However, thrombus was seldom observed on the predilatation angiogram in the present study, although unstable angina, in which the presence of intracoronary thrombus is frequently observed, ${ }^{23,24}$ was a risk factor for a major adverse cardiac event. In this study, patients with unstable angina were aggressively treated with intravenous heparin that may have effectively dealt with intracoronary thrombus in some cases. Therefore, thrombus was not a remarkable angiographic feature in the study.

In contrast with Black et al, ${ }^{9}$ the balloon-artery ratio was not a factor for predicting major adverse cardiac events in the present study, although there was a differcnce in definition. Because of such previously published findings, many investigators may have carefully ensured appropriate matching of balloon with artery size.

From the literature, one would expect that dilation of type $\mathrm{C}$ lesions would be a risk factor for a major adverse cardiac event, because it is associated with a $<60 \%$ acute success rate according to the American College of Cardiology/Amcrican Heart Association Task Force. ${ }^{22}$ However, a recent study of 1,000 lesions by Myler et $\mathrm{a}^{25}$ reported an angioplasty success rate of $90 \%$ for type $\mathrm{C}$ lesions, which was only slightly less than that for type A and B. In the present study, type C lesions were predictive of major adverse cardiac events in univariate but not multivariate analysis. The relatively high discordance between observers suggests that the use of this subjective evaluation should be cautiously interpreted. ${ }^{26}$

Study limitations: The study cohort of this retrospective analysis comprised patients recruited for 2 multicenter, restenosis, pharmacologic prevention trials in Europe. Although in both trials, consecutive patients of the participating clinics were recruited, only $25 \%$ of those undergoing angioplasty were recruited, because $\geq 1$ specific exclusion criterion was found. ${ }^{15,16}$

In the CARPORT trial, patients treated with the new thromboxane A2-receptor blockade did not receive aspirin before or during the angioplasty procedure, but all others did; this may have influenced the incidence of major adverse cardiac events. ${ }^{27}$

Although the Cardiovascular Angiography Analysis System has been validated and extensively described in the literature, validation studies of quantitatively derived, lesion morphologic characteristics such as lesion length and eccentricity, and vessel curvature have not been performed. ${ }^{13}$

Coronary angiography, as a 2-dimensional silhouette of the vessel lumen, is inherently limited for the assessment of atherosclerotic plaque morphology, as has been increasingly demonstrated by intravascular ultrasound techniques. ${ }^{28}$ Furthermore, the use of objective quantitative analysis does not provide insight to the prediction of major adverse cardiac events from angiographic measurements and lesion morphology. Newer and more sophisticated quantitative analysis systems may be more helpful in this regard 29 ; however, the combined use of intracoronary angioscopy and ultrasound is more likely to shed new light on the continued unpredictability of major adverse cardiac events after coronary interventions.

Acknowledgment: The logistic and technical support of Jaap Pameijer, RN, and the statistical advice of Jaap W. Deckers, MD, is greatly appreciated.

1. Cowley MJ, Dorros G, Kelsey SF, Van Raden M, Detre KM. Acute coronary events associated with percutaneous transluminal coronary angioplasty. Am I Cardiol 1983;53:12C-16C.

2. Bredlau CE, Roubin GS, Leimgruber PP, Douglas JS Jr, King SB III, Gruentzig AR. In-hospital morbidity and mortality in patients undergoing elective coronary angioplasty. Circulation 1985;72:1044-1052.

3. Ellis SG, Roubin GS, King SB III, Douglas JS Jr, Weintraub WS, Thomas RG, Cox WR. Angiographic and clinical predictors of acute closure after native vessel coronary angioplasty. Circulation 1988;77:372-379.

4. Detre KM, Ilolmes IS Jr, Ilolubkov R, Cowley MJ, Dourassa MG, Faxon DP, Dorros GR, Bentivoglio LG, Kent KM, Myler RK, and coinvestigators of the National Heart, Lung, and Blood Institute's Percutaneous Transluminal Coronary Angioplasty Registry. Incidence and consequences of periprocedural occlusion. The 1985-1986 National Heart, Lung, and Blood Institute Percutaneous Transluminal Coronary Angioplasty Registry. Circulation 1990;82:739-750.

5. De Feyter PJ, van den Brand M, Laarman GJ, van Domburg R, Serruys PW, Suryapranata $\mathrm{H}$. Acute coronary artery occlusion during and after percutaneous transluminal coronary angioplasty. Frequency, prediction, clinical course, management, and follow-up. Circulation 1991;83:927-936.

6. Lincoff AM, Popma JJ, Ellis SG, Hacker JA, Topol EJ. Abrupt vessel closure complicating coronary angioplasty: clinical, angiographic and therapeutic profile. $J$ Am Coll Cardiol 1992;19:926-935.

7. Ischinger T, Gruentzig AR, Meier B, Galan K. Coronary dissection and total coronary occlusion associated with percutaneous transluminal coronary angioplasty: significance of initial angiographic morphology of coronary stenoses. Circulation 1986;74:1371 1378.

8. Ellis SG, Roubin GS, King SB III, Douglas JS Jr, Shaw RE, Stertzer SH, Myler RK. In-hospital cardiac mortality after acute closure after coronary angioplasty: analysis of risk factors from 8,207 procedures. I Am Coll Cardiol 1988;11:211-216.

9. Black AJR, Namay DL, Niederman AL, Lembo NJ, Roubin GS, Douglas JS Jr, King SB III. Tear or dissection after coronary angioplasty. Morphologic correlates of an ischemic complication. Circulation 1989;79:1035-1042.

10. Zir LM, Miller SW, Dinsmore RE, Gilbert JP, Harthorne JW. Interobserver variability in coronary angiography. Circulation 1976;55:627-632.

11. Beaumann GJ, Vogel RA. Accuracy of individual and panel visual interpretations of coronary arteriograms: implications for clinical decisions. I Am Coll Cardiol 1990;16:108-113.

12. Fleming RM, Kirkeeide RL, Smalling RW, Gould KL, Stuart Y. Patterns in visual interpretation of coronary arteriograus detected by quantitative coronary arteriography. J Am Coll Cardiol 1991;18:945-951.

13. Reiber JHC, Serruys PW. Quantitative coronary angiography. In: Marcus ML, Schelbert HR, Skorton DJ, Wolf GL, eds. Cardiac Imaging: A Companion to Braunwaid's Heart Disease. Philadelphia: WB Saunders, 1990:211-280.

14. Hermiller JB, Cusma JT, Spero LA, Fortin DF, Harding MB, Bashore TM. Quantitative and qualitative coronary angiographic analysis: review of methods, utility and limitations. Cathet Cardiovasc Diagn 1992;25:110-131.

15. Serruys PW, Rutsch W, Heyndrickx GR, Danchin N, Mast EG, Wijns W, Rensing BJ, Vos J, Stibbe J. Prevention of restenosis after percutaneous transluminal coronary angioplasty with thromboxane A2 receptor blockade. A randomized, double blind, placebo controlled trial. Circulation 1991;84:1568--1580. 16. MERCATOR study group. Does the new angiotensin converting enzyme inhibitor cilazapril prevent restenosis after percutaneous transluminal coronary angioplasty? The results of the MERCATOR study: a multicenter randomized double-blind placebo-controlled trial. Circulation 1992;86:100-110.

17. Campeau L. Grading of angina pectoris. Circulation 1976;54:522-523.

18. Austen WG, Edwards JE, Frye RL, Gensini GG, Gott VL, Griffith LSC, McGoon DC, Murphy ML, Roe BB. A reporting system in patients evaluated for grading of coronary artery disease. Report of the Ad Hoc Committee for Grading Cornnary Artery Disease, Council on Cardiovascular Surgery, American Heart Association. Circulation 1975;51:7-40.

19. Ambrose JA, Winters SL, Stern A, Eng A, Teichholz LE, Gorlin R, Fuster V. Angiographic morphology and the pathogenesis of unstable angina pectoris. $J \mathrm{Am}$ Coll Cardiol 1985;5:609-616.

20. Ellis SG, Roubin GS, King SB III, Douglas JS Jr, Cox WR. Importance of stenosis morphology in the estimation of restenosis after successful coronary angioplasty. Am J Cardiol 1989;63:30-34.

21. Mabin TA, Holmes DR Jr, Smith HC, Vlietstra RE, Bove AA, Reeder GS, Chescbro JH, Bresnahan JF, Orszulak TA. Intracoronary thrombus: role in coro- 
nary occlusion complicating percutaneous transluminal coronary angioplasty. $J \mathrm{Am}$ Coll Cardiol 1985;5:198-202

22. Ryan TJ, Faxon DP, Gunnar RM, Kennedy JW, King SB, Loop FD, Peterson KL, Reeves TJ, Williams DO, Winters WL, Fisch C, DeSanctis RW, Dodge HT, Weinberg SL. ACC/AHA Task Force Report: guidelines for percutaneous transluminal coronary angioplasty. A report of College/American Heart Association Task Force on assessment of diagnosric and therapeutic cardiovascular procedures (subcommittee on percutaneous transluminal coronary angioplasty). $J$ Am Coll Cardiol $1988 ; 12: 529-545$.

23. Knopf WD, Cates CU, Doby B, Langlois K. Coronary angioscopy influences intervention in patients with unstable angina and recent myocardial infarction (abstr). Circulation 1992;86:I-651.

24. Fuster V, Badimon L, Cohen M, Ambrose IA, Badimon JJ, Chesebro JH. Insights into the pathogenesis of acute ischemic syndromes. Circulation 1988;77: $1213-1220$.

25. Myler RK, Shaw RE, Stertzer SH, Hecht HS, Ryan C, Rosenblum J, Cum- berland DC, Murphy MC, Hansell HN, Hidalgo B. Lesion morphology and coronary angioplasty: current experience and analysis. J Am Coll Cardiol 1992;19: 1641-1652.

26. Kleiman NS, Rodriguez $A R$, Raizner $A E$. Interobserver variability in grading of coronary arterial narrowings using the American College/American Heart Association grading criteria. Am J Cardiol 1992;69:413-415.

27. Schwartz L, Bourassa MG, Lesperance J, Aldridge HE, Kazim F, Salvator VA, Henderson M, Bonan R, David PR. Aspirin and dipyridamole in the prevention of restenosis after percutaneous transluminal coronary angioplasty. $N E n g l J$ Med 1988;318:1714-1719.

28. Hooyne J, Mahon DJ, Jain A, White CJ, Ramee SR, Wallis JB, Zarka AA Tobis JM. Morphological effects of coronary balloon angioplasty in vivo assessed by intravascular ultrasound imaging. Circulation 1992;85:1012-1025.

29. Kalbfleisch SJ, McGillem MJ, Simon SB, DeBoe SF, Pinto IMF, Mancini GBJ. Automated quantitation of indexes of coronary lesion complexity: comparison between patients with stable and unstable angina. Circulation 1990;82:439-447. 